\title{
Autolyzed Saccharomyces cerevisiae as a single cell protein for broiler diet
}

\section{Moniruzzaman M and MBR Mollah*}

Poultry Biotechnology and Genomics Laboratory, Department of Poultry Science, Faculty of Animal Husbandry, Bangladesh Agricultural University, Mymensingh-2202, Bangladesh

\begin{abstract}
Microbial protein often called as single cell proteins (SCP) are becoming a potential alternative to conventional protein rich ingredients in poultry diet. An experiment was conducted to know the possibility of using Saccharomyces cerevisiae derived SCP in broiler diet. A total of 96 male Ross-308 day old chicks were assigned to four diet comprising control (0\% replacement), $25 \%$ replacement, $50 \%$ replacement and $100 \%$ replacement of protein concentrate with autolyzed $S$. cerevisiae. Each group had 6 replicates of 4 chicks in each. Body weight, body weight gain, daily weight gain, feed intake and feed conversion ratio were not affected $(P>0.05)$ in case of $25 \%$ and $50 \%$ replacements. However, $100 \%$ replacement had resulted numerically negative effect as compared to control group. Dressing percentage and other carcass characteristics were not affected $(P>0.05)$ in the replacement groups. The results of this study indicated that autolyzed $S$. cerevisiae might be used to replace protein concentrate at $25 \%$ to $50 \%$ level in broiler diet without affecting growth and carcass quality.
\end{abstract}

Key words: Saccharomyces cerevisiae, protein concentrate, broiler, single cell protein

Bangladesh Animal Husbandry Association. All rights reserved.

Bang. J. Anim. Sci. 2019. 48 (1):1-8

\section{Introduction}

Commercial poultry farming is playing a vital role in providing cheap animal protein to human diet in Bangladesh. However, most of the inputs for commercial poultry farming are of imported origin (Chowdhury, 2013). Thus, Bangladesh is spending substantial amount of foreign currency every year to import feed ingredients like protein concentrates and soyabean meal. This situation is creating a demand for the formulation of innovative and alternative proteinaceous feed sources for livestock and poultry. Single cell protein (SCP) production might be a major step in this direction. SCP is the protein extracted from cultivated microbial biomass (Nasseri et al., 2011). It can be used for protein supplementation of a staple diet by replacing costly conventional sources like soymeal, protein concentrate and fishmeal. In addition, bioconversion of agro industrial wastes to protein rich feed ingredients has an additional benefit of making the final product cheaper. This would also offset the negative cost value of wastes used as substrate to yield SCP. Further, it would make feed production less dependent upon land and relieve the pressure on agriculture. SCP are being produced from various microorganisms such as algae, bacteria, fungi and yeasts for both human and livestock.
Due to ease of propagation using cheap agro industrial byproducts and isolation; yeasts, specially Saccharomyces cerevisiae (S. cerevisiae) has become more convenient source of SCP (Ravindra, 2000; Bekatorou et al., 2006; Nasseri et al., 2011). To date, numerous potential strains of microbes and substrates that could be utilized for SCP production are proposed. However, nutritive value and removal of nucleic acids and toxins from SCP as a protein source is crucial before being considered a particular SCP for poultry diet.

S. cerevisiae is a good source of various nutrients like crude protein, amino acids, fatty acid, mineral elements, vitamin, etc., and could be a potential options for producing SCP (Yamada and Sgarbieri, 2005; Bacha et al., 2011; Yassine et al., 2013). SCP derived from S. cerevisiae contains $44.40 \%$ crude protein, $1 \%$ crude fat, $2.70 \%$ crude fiber, $0.12 \%$ Calcium and $1.40 \%$ Phosphorus and also $1,990 \mathrm{Kcal} / \mathrm{Kg}$ metabolizable energy (Shahryar et al., 2012; Chand et al., 2014). In addition, the cell wall fraction is rich in glycan and mannanoligosaccharides (MOS), which enhance growth of gut probiotic bacteria in poultry (Fernandez et al., 2002). Use of $S$. cerevisiae as a protein source in poultry feed requires destruction of cell wall to release the cell contents. The destruction process can be

*Corresponding author: mbrmollah.ps@bau.edu.bd 


\section{Saccharomyces cerevisiae in broiler diet}

accomplished by autolysis. The most common method of autolysis is heat treatment and changing the $\mathrm{pH}$ of the media. S. cerevisiae, either whole or autolyzed is being used as supplementation in broiler diets to improve different growth parameters (Gao et al., 2008). However, the question of using autolysed $S$. cerevisiae as a replacement of commercial protein concentrate is still open. Thus, this study was conducted to replace commercial protein concentrate with SCP derived from autolyzed S. cerevisiae in broiler diet.

\section{Materials and Methods}

\section{Production and autolysis of $S$. cerevisiae biomass}

Molasses based media was used as the carbon source for mass production of $S$. cerevisiae. Sugarcane molasses was collected from the local market and $15 \%$ media was prepared with normal tap water and the Brix value was adjusted to $11^{\circ}$. The $\mathrm{pH}$ of the media was adjusted to 5.26. Commercial grade urea was added $6 \mathrm{gL}^{-1}$ to increase nitrogen content of the media. $1.8 \mathrm{~L}$ of previously prepared $S$. cerevisiae pure stock was inoculated to $350 \mathrm{~L}$ growth medium following autoclave at $121^{\circ} \mathrm{C}$ and 15 PSI for 30 minutes and cooling. The fermentation process was carried out within a customized bioreactor at 28$30^{\circ} \mathrm{C}$ for 72 hours. During the culturing process, 15 litre/minute purified air was supplied to the media to maintain aerobic condition. S. cerevisiae was harvested by gravitational method. Then the cells were washed with distilled water and autolyzed at $55^{\circ} \mathrm{C}$ for 36 hours. After autolysis, the autolyzed S. cerevisiae was kept at $80^{\circ} \mathrm{C}$ for 30 mins to stop the autolysis process as described by Tangüler and Erten (2009). Then the autolysate was dried at $60^{\circ} \mathrm{C}$ to remove moisture.

\section{Feeding trial}

Oven dried autolyzed S. cerevisiae was used to replace the protein concentrate at $25 \%, 50 \%$ and $100 \%$ in feed. Experimental diets were formulated to meet up the nutrients requirement of ROSS-308 using high quality commonly available feed ingredients. The diets were formulated for starter and grower phases (ingredients and nutritional composition are presented in Table 1 and Table 2, respectively) and presented to the birds in mash form. The chicks were randomly assigned to different dietary groups in a completely randomized design (CRD). The duration of the experiment was 35 days.

Table 1. Ingredients and nutritional composition of starter diet (0-21 day)

\begin{tabular}{lcccc}
\hline \multirow{2}{*}{ Ingredients (\%) } & \multicolumn{4}{c}{ Level of replacement } \\
\cline { 2 - 5 } Maize & $\mathbf{0 \%}$ & $\mathbf{2 5 \%}$ & $\mathbf{5 0 \%}$ & $\mathbf{1 0 0 \%}$ \\
Protein concentrate & 51.0 & 49.30 & 48.0 & 45.80 \\
Yeast autolysate & 5.0 & 3.75 & 2.50 & 0 \\
Soybean meal & 0 & 1.25 & 2.50 & 5.0 \\
Soybean oil & 37.60 & 38.80 & 39.70 & 41.60 \\
Di-Calcium Phosphate & 3.0 & 3.50 & 3.80 & 4.0 \\
L-Lysine & 2.50 & 2.55 & 2.70 & 2.80 \\
DL-Methionine & 0.20 & 0.18 & 0.18 & 0.18 \\
Vitamin premix* & 0.20 & 0.18 & 0.18 & 0.18 \\
Common salt & 0.25 & 0.25 & 0.25 & 0.25 \\
Total & 0.25 & 0.25 & 0.20 & 0.20 \\
Diet compositions & 100 & 100 & 100 & 100 \\
Crude protein (\%) & & & & 22.45 \\
Metabolizable energy (Kcal/Kg) & 22.58 & 22.57 & 22.49 & 2995 \\
Calcium (\%) & 3010 & 3011 & 3001 & 0.88 \\
Available Phosphorus (\%) & 0.96 & 0.93 & 0.93 & 0.61 \\
Lysine (\%) & 0.62 & 0.62 & 0.63 & 1.44 \\
Methionine (\%) & 1.51 & 1.48 & 1.41 & 0.55
\end{tabular}

*Vitamin premix supplied per kilogram of diet: vitamin A, 11,000 IU; vitamin D3, 4,500 IU; vitamin E, 70 IU; vitamin K, 3 mg; vitamin B1, $3.2 \mathrm{mg}$; vitamin B2, $8.4 \mathrm{mg}$; vitamin B6, $4.1 \mathrm{mg}$; D-pantothenic acid, $20.0 \mathrm{mg}$; niacin, $65 \mathrm{mg}$; biotin, $0.25 \mathrm{mg}$; folic acid, $2 \mathrm{mg}$; vitamin B12, $0.02 \mathrm{mg}$. 
Moniruzzaman and Mollah (2019) Bang. J. Anim. Sci. 48 (1):1-8

Table 2. Ingredients and nutritional composition of grower diet (22-35 day)

\begin{tabular}{lcccc}
\hline \multirow{2}{*}{ Ingredients (\%) } & \multicolumn{4}{c}{ Level of replacement } \\
\cline { 2 - 5 } & $\mathbf{0 \%}$ & $\mathbf{2 5 \%}$ & $\mathbf{5 0 \%}$ & $\mathbf{1 0 0 \%}$ \\
\hline Maize & 55.7 & 54.6 & 52.9 & 50.1 \\
Protein concentrate & 5 & 3.75 & 2.5 & 0 \\
Yeast autolysate & 0 & 1.25 & 2.5 & 5 \\
Soybean meal & 32.6 & 33.35 & 34.45 & 36.15 \\
Soybean oil & 3.7 & 4.1 & 4.6 & 5.4 \\
Di-Calcium Phosphate & 2.1 & 2.2 & 2.3 & 2.6 \\
L-Lysine & 0.2 & 0.15 & 0.15 & 0.15 \\
DL-Methionine & 0.2 & 0.15 & 0.15 & 0.15 \\
Vitamin premix* & 0.25 & 0.25 & 0.25 & 0.25 \\
Common salt & 0.25 & 0.2 & 0.2 & 0.2 \\
Total & 100 & 100 & 100 & 100 \\
Diet compositions & & & & 20.7 \\
Crude protein (\%) & 20.9 & 20.8 & 20.8 & 3098 \\
Metabolizable energy (Kcal/Kg) & 3103 & 3104 & 3102 & 0.83 \\
Calcium (\%) & 0.86 & 0.84 & 0.83 & 0.6 \\
Available Phosphorus (\%) & 0.5 & 0.5 & 0.5 & 1.28 \\
Lysine (\%) & 1.39 & 1.32 & 1.26 & 0.50 \\
Methionine (\%) & 0.59 & 0.53 & 0.51 & IV
\end{tabular}

*Vitamin premix supplied per kilogram of diet: vitamin A, 11,000 IU; vitamin D3, 4,500 IU; vitamin $\mathrm{E}_{1} 70 \mathrm{IU}$; vitamin K, $3 \mathrm{mg}$; vitamin B1, $3.2 \mathrm{mg}$; vitamin B2, $8.4 \mathrm{mg}$; vitamin B6, $4.1 \mathrm{mg}$; D-pantothenic acid, $20.0 \mathrm{mg}$; niacin, $65 \mathrm{mg}$; biotin, $0.25 \mathrm{mg}$; folic acid, $2 \mathrm{mg}$; vitamin B12, $0.02 \mathrm{mg}$.

\section{Management of experimental broilers}

Day old chicks were collected from local commercial hatchery and individually identified by wing banding and randomly assigned into four dietary groups; control group $(0 \%)$, three replacement groups $(25 \%, 50 \%$ and $100 \%)$ with 24 chicks per group. The experiment was conducted at the open sided house of Bangladesh Agricultural University Poultry Farm. $5 \mathrm{~cm}$ deep rice husk was used as litter material. One chick feeder and drinker were provided in each pen. The feeders and drinkers were fixed in such a way that the broilers were able to eat and drink conveniently. Drinkers were washed and cleaned everyday while feeder were cleaned once in a week. Feed and fresh drinking water was supplied ad-libitum basis. Birds were vaccinated against Infectious Bronchitis (IB), New castle Disease (ND) and Infectious Bursal Diseases (IBD). Standard biosecurity measures were followed throughout the rearing period.

\section{Data collection and record keeping}

Weekly body weights of individual bird and weight of feed given and left over were measured and recorded. Live body weight (LBW), body weight gain (BWG), feed intake (FI) and feed conversion ratio (FCR) were calculated for each growth phases. At the end of the feeding trial, one broiler per replication having similar body weight was sacrificed and used for recording different carcass parameters. The birds were sacrificed and allowed to bleed completely and scalded by immersing in hot water $\left(51-55^{\circ} \mathrm{C}\right)$ for $2 \mathrm{~min}$. The feathers were removed by hand pinning. Finally, records were kept on weight of dressed broilers, feather, blood, shank, liver, heart, gizzard, spleen, head, neck and intestine. The contents of gizzard were expelled to record its weight.

\section{Statistical analysis}

Collected data were analyzed using a linear model implemented in $\mathrm{R}$ ( $\mathrm{R}$ Core Team, 2016). Effect of diets, individual and replication were treated as fixed effects. Diet effects on different body weight, growth and carcass parameters were compared with control diet by Dunnett's test.

\section{Results}

\section{Body weight}

Body weight ( $g$ ) of chicks fed different diets replaced with autolyzed $S$. cerevisiae is presented in Table 3. Insignificant difference $(P=0.8580)$ of initial body weight was found among the dietary groups. However, the effect of replacing protein concentrate with autolyzed $\mathrm{S}$. cerevisiae was signficant at 7, 14, 21 and 28 days of age. In contrary, the effect was insignificant $(P=0.1150)$ at 35 days of age. No significant differences in body weight was observed in $25 \%$ and $50 \%$ replacement group as compared to control group ( $0 \%$ replacement) at 7 days of age, whereas significantly $(P<0.05)$ lower body weight was 


\section{Saccharomyces cerevisiae in broiler diet}

observed in $100 \%$ replacement group as compared to control group. However, no significant difference in body weight was observed in $25 \%$ replacement group as compared to control group at 14 days; whereas significantly $(P<0.01)$ lower body weights were observed in $50 \%$ and $100 \%$ replacement group. Similar trends of body weight were observed at 21 days of age in $25 \%$ replacement group as compared to control group, but significantly $(P<0.05)$ lower body weights were observed in $50 \%$ and $100 \%$ replacement group.
At 28 days, $25 \%$ and $50 \%$ replacement group showed insignificant $(P>0.05)$ difference in body weight as compared to control group while $100 \%$ replacement group showed significantly $(P<0.05)$ lower body weight. At the age of 35 days, there was no significant difference in body weight among different dietary groups was found, but numerically lower value was observed in $100 \%$ replacement group which is statistically nonsignificant $(P=0.1150)$.

Table 3. Body weight $(\mathrm{g}$ ) of chicks fed different diets replaced with autolyzed S. cerevisiae

\begin{tabular}{lccccc}
\hline $\begin{array}{l}\text { Age } \\
\text { (days) }\end{array}$ & \multicolumn{5}{c}{ Level of replacement } \\
\cline { 2 - 6 } & $\mathbf{0 \%}$ & $\mathbf{2 5 \%}$ & $\mathbf{5 0 \%}$ & $\mathbf{1 0 0 \%}$ & P-value \\
\hline 0 & $48.44 \pm 2.10$ & $48.89 \pm 2.04$ & $49.10 \pm 1.97$ & $48.94 \pm 1.39$ & 0.8580 \\
7 & $165.83 \pm 19.85$ & $165.38 \pm 17.61^{\mathrm{NS}}$ & $149.17 \pm 17.37^{\mathrm{NS}}$ & $147.25 \pm 17.30^{*}$ & $1.18 \times 10^{-2}$ \\
14 & $381.38 \pm 58.16$ & $371.92 \pm 50.72^{\mathrm{NS}}$ & $303.54 \pm 71.92^{* *}$ & $302.38 \pm 44.00^{* *}$ & $6.24 \times 10^{-4}$ \\
21 & $694.63 \pm 105.41$ & $664.58 \pm 125.00^{\mathrm{NS}}$ & $583.58 \pm 134.58^{*}$ & $581.92 \pm 76.69^{*}$ & 0.0259 \\
28 & $1022.33 \pm 146.06$ & $1052.67 \pm 171.29^{\mathrm{NS}}$ & $948.71 \pm 248.78^{\mathrm{NS}}$ & $910.83 \pm 127.25^{*}$ & 0.0275 \\
35 & $1654.09 \pm 166.65$ & $1637.92 \pm 237.23$ & $1510.58 \pm 325.04$ & $1453.08 \pm 162.08$ & 0.1150 \\
\hline $\begin{array}{l}\text { Data are Mean } \pm \text { SD. NS: non-significant, } *: P<0.05, * *: P<0.01 \text { compared to control diet }(0 \% \text { replacement) as } \\
\text { determined by Dunnett's test }\end{array}$ & & & &
\end{tabular}

Table 4. Body weight gain ( $\mathrm{g}$ ) of chicks fed different diets replaced with autolyzed S. cerevisiae

\begin{tabular}{lccccc}
\hline \multirow{2}{*}{ Age (days) } & \multicolumn{5}{c}{ Level of replacement } \\
\cline { 2 - 5 } & $\mathbf{0 \%}$ & $\mathbf{2 5 \%}$ & $\mathbf{5 0 \%}$ & $\mathbf{1 0 0 \%}$ & \multirow{2}{*}{-value } \\
\hline $0-7$ & $117.39 \pm 20.02$ & $116.49 \pm 16.82^{\mathrm{NS}}$ & $100.07 \pm 17.31^{\mathrm{NS}}$ & $98.31 \pm 17.16^{*}$ & 0.0089 \\
$7-14$ & $215.54 \pm 39.59$ & $206.54 \pm 37.29^{\mathrm{NS}}$ & $154.38 \pm 59.06^{* *}$ & $155.13 \pm 32.72^{* *}$ & $6.93 \times 10^{-5}$ \\
$14-21$ & $313.25 \pm 60.61$ & $292.67 \pm 79.62$ & $280.04 \pm 74.15$ & $279.54 \pm 50.61$ & 0.5418 \\
$21-28$ & $412.59 \pm 58.87$ & $388.08 \pm 62.57$ & $365.13 \pm 123.82$ & $328.92 \pm 108.46$ & 0.173 \\
$28-35$ & $538.82 \pm 85.85$ & $585.25 \pm 92.46$ & $561.88 \pm 115.55$ & $542.25 \pm 86.40$ & 0.646 \\
$0-21$ & $646.18 \pm 105.36$ & $615.70 \pm 124.42^{N S}$ & $534.49 \pm 134.54 *$ & $532.97 \pm 76.41^{*}$ & 0.0247 \\
$21-35$ & $951.41 \pm 124.21$ & $973.33 \pm 141.67$ & $927.00 \pm 208.75$ & $871.17 \pm 117.68$ & 0.420 \\
$0-35$ & $1605.92 \pm 166.34$ & $1589.03 \pm 236.75$ & $1461.49 \pm 324.99$ & $1404.14 \pm 161.47$ & 0.113
\end{tabular}

Data are Mean \pm SD. ${ }^{N S}$ : non-significant, $*: P<0.05, * *: P<0.01$ compared to control diet ( $0 \%$ replacement) as determined by Dunnett's test. 
Moniruzzaman and Mollah (2019) Bang. J. Anim. Sci. 48 (1):1-8

Table 5. Feed intakes ( $\mathrm{g}$ ) of chicks fed different diets replaced with autolyzed $\mathrm{S}$. cerevisiae

\begin{tabular}{lccccc}
\hline \multirow{2}{*}{ Age (days) } & \multicolumn{5}{c}{ Level of replacement } \\
\cline { 2 - 6 } & $\mathbf{0 \%}$ & $\mathbf{2 5 \%}$ & $\mathbf{5 0 \%}$ & $\mathbf{1 0 0 \%}$ & P-value \\
\hline $0-7$ & $168.33 \pm 3.23$ & $168.96 \pm 3.43$ & $164.17 \pm 4.04$ & $159.92 \pm 4.27$ & 0.101 \\
$7-14$ & $409.54 \pm 9.76$ & $428.46 \pm 1.25$ & $408.67 \pm 33.55$ & $412.08 \pm 4.69$ & 0.535 \\
$14-21$ & $598.83 \pm 59.00$ & $665.46 \pm 31.68$ & $576.67 \pm 122.92$ & $604.50 \pm 48.77$ & 0.557 \\
$21-28$ & $909.58 \pm 86.24$ & $918.25 \pm 73.40$ & $873.17 \pm 152.13$ & $919.92 \pm 71.38$ & 0.941 \\
$28-35$ & $1013.42 \pm 150.51$ & $1090.92 \pm 53.13$ & $1070.83 \pm 11.27$ & $1086.67 \pm 26.02$ & 0.610 \\
$0-21$ & $1176.71 \pm 70.82$ & $1262.88 \pm 30.65$ & $1149.50 \pm 155.32$ & $1176.50 \pm 49.35$ & 0.513 \\
$21-35$ & $1923.00 \pm 236.66$ & $2009.17 \pm 95.99$ & $1944.00 \pm 153.25$ & $2006.58 \pm 96.90$ & 0.854 \\
$0-35$ & $3099.71 \pm 250.80$ & $3272.04 \pm 125.94$ & $3093.50 \pm 302.01$ & $3183.08 \pm 136.74$ & 0.711 \\
\hline Data are Mean & I Standard deviation & & & &
\end{tabular}

Table 6. FCR of chicks fed different diets replaced with autolyzed S. cerevisiae

\begin{tabular}{llllll}
\hline \multirow{2}{*}{ Age (days) } & \multicolumn{5}{c}{ Level of replacement } \\
\cline { 2 - 5 } & $\mathbf{0 \%}$ & $\mathbf{2 5 \%}$ & $\mathbf{5 0 \%}$ & $\mathbf{1 0 0 \%}$ & P-value \\
\hline $0-7$ & $1.44 \pm 0.08$ & $1.45 \pm 0.09$ & $1.65 \pm 0.18$ & $1.65 \pm 0.24$ & 0.0867 \\
$7-14$ & $1.90 \pm 0.07$ & $2.11 \pm 0.34$ & $2.82 \pm 0.81$ & $2.68 \pm 0.30$ & 0.151 \\
$14-21$ & $1.94 \pm 0.33$ & $2.42 \pm 0.84$ & $2.05 \pm 0.15$ & $2.20 \pm 0.44$ & 0.676 \\
$21-28$ & $2.42 \pm 0.17$ & $2.38 \pm 0.30$ & $2.43 \pm 0.25$ & $2.86 \pm 0.62$ & 0.386 \\
$28-35$ & $2.04 \pm 0.21$ & $1.87 \pm 0.13$ & $1.92 \pm 0.23$ & $2.03 \pm 0.24$ & 0.760 \\
$0-21$ & $1.83 \pm 0.19$ & $2.11 \pm 0.48$ & $2.16 \pm 0.12$ & $2.23 \pm 0.32$ & 0.379 \\
$21-35$ & $2.20 \pm 0.07$ & $2.07 \pm 0.20$ & $2.12 \pm 0.20$ & $2.31 \pm 0.12$ & 0.416 \\
$0-35$ & $2.12 \pm 0.17$ & $2.08 \pm 0.29$ & $2.13 \pm 0.15$ & $2.28 \pm 0.19$ & 0.653 \\
\hline
\end{tabular}

Data are Mean \pm Standard deviation

\section{Body weight gain}

Body weight gain $(\mathrm{g})$ of chicks fed different diets replaced with autolyzed $S$. cerevisiae are shown in Table 4. The effects of replacing protein concentrate with autolyzed $S$. cerevisiae was signficant during $0-7,7-14$, and $0-21$ days of age. In contrary, the effect was non-significant in $14-21,21-28,28-35,21-35$ and 0-35 days of age. During 0-7 days of rearing, no significant difference in body weight gain was observed in $25 \%$ and $50 \%$ replacement group as compared to control group ( $0 \%$ replacement), whereas significantly $(P<0.05)$ lower body weight gain was observed in $100 \%$ replacement group as compared to control group.

\section{Feed intake and FCR}

Table 5 represents feed intake $(g)$ of chicks fed different diets replaced with autolyzed $S$. cerevisiae. Irrespective of stages of growth, the effect of replacing protein concentrates with autolyzed $S$. cerevisiae had no effects on feed intake. However, numerically higher but statistically insignificant feed intake was observed in $25 \%$ and $100 \%$ replacement group as compared to control group, whereas $50 \%$ replacement group showed the lower feed intake.

FCR of chicks fed different diets replaced with autolyzed S. cerevisiaeis represented in Table 6 . The effect of replacing protein concentrate with autolyzed $S$. cerevisiae was insignificant throughout the trial period. However, statistically insignificant but numerically lower FCR was observed in $25 \%$ replacement group whereas $100 \%$ replacement group showed the higher.

\section{Carcass characteristics}

Carcass characteristics and organ weights of broilers fed different diets replaced with autolyzed S. Cerevisiae are shown in Table 7. 
Saccharomyces cerevisiae in broiler diet

Table 7. Carcass characteristics of broilers fed different diets replaced with autolyzed S. cerevisiae

\begin{tabular}{lccccc}
\hline \multirow{2}{*}{ Parameters } & \multicolumn{5}{c}{ Level of replacement } \\
\cline { 2 - 5 } & $\mathbf{0 \%}$ & $\mathbf{2 5 \%}$ & $\mathbf{5 0 \%}$ & $\mathbf{1 0 0 \%}$ & P-value \\
\hline Dressing percentage (\%) & $66.66 \pm 2.99$ & $66.67 \pm 2.57$ & $65.83 \pm 1.39$ & $66.12 \pm 1.17$ & 0.951 \\
Blood wt (\%) & $3.10 \pm 1.10$ & $3.60 \pm 1.25$ & $4.13 \pm 0.83$ & $3.97 \pm 0.26$ & 0.568 \\
Feather wt (\%) & $3.38 \pm 0.28$ & $4.80 \pm 0.21^{* * *}$ & $3.50 \pm 0.07^{\mathrm{NS}}$ & $3.72 \pm 0.15^{\mathrm{NS}}$ & $6.61 \times 10^{-5}$ \\
Shank wt (\%) & $4.24 \pm 0.45$ & $4.16 \pm 0.23$ & $4.61 \pm 0.38$ & $4.58 \pm 0.22$ & 0.308 \\
Head wt (\%) & $3.17 \pm 0.08$ & $3.40 \pm 0.07^{\mathrm{NS}}$ & $3.11 \pm 0.08^{\mathrm{NS}}$ & $2.78 \pm 0.20^{*}$ & 0.00156 \\
Neck wt (\%) & $1.97 \pm 0.41$ & $1.79 \pm 0.15$ & $2.68 \pm 0.30$ & $2.36 \pm 0.39$ & 0.0421 \\
Abdominal fat (\%) & $1.04 \pm 0.23$ & $0.98 \pm 0.09$ & $1.07 \pm 0.11$ & $0.72 \pm 0.08$ & 0.0537 \\
Liver wt (\%) & $2.42 \pm 0.24$ & $2.27 \pm 0.19$ & $2.20 \pm 0.11$ & $2.23 \pm 0.12$ & 0.467 \\
Gizzard wt (\%) & $2.21 \pm 0.16$ & $1.91 \pm 0.26$ & $2.30 \pm 0.06$ & $2.17 \pm 0.22$ & 0.161 \\
Spleen wt (\%) & $0.09 \pm 0.03$ & $0.12 \pm 0.03$ & $0.13 \pm 0.03$ & $0.10 \pm 0.01$ & 0.443 \\
Heart wt (\%) & $0.56 \pm 0.05$ & $0.59 \pm 0.15$ & $0.62 \pm 0.15$ & $0.54 \pm 0.07$ & 0.844 \\
Intestine wt (\%) & $8.83 \pm 2.06$ & $8.40 \pm 0.83$ & $8.09 \pm 1.60$ & $8.83 \pm 0.76$ & 0.899 \\
\hline
\end{tabular}

Data are Mean \pm SD. Ns: non-significant, $* * *: P<0.001$ compared to control diet ( $0 \%$ replacement) as determined by Dunnett's test

The effect of replacing protein concentrate with autolyzed $S$. cerevisiae was insignificant in different carcass characteristics parameter among the dietary groups except feather and head weight. Significantly $(P<0.001)$ higher feather (\%) was observed in $25 \%$ replacement group. $100 \%$ replacement group resulted significantly $(P<0.05)$ lower head weight as compared to control group.

\section{Discussion}

\section{Body weight and body weight gain}

Autolyzed S. cerevisiae was used to replace commercial protein concentrate in broiler ration. Partial replacement of protein concentrate did not significantly affect body weight, body weight gain, feed intake, FCR and carcass characteristics. S. cerevisiae is rich in protein, balanced amino acids, B-complex vitamins and minerals (Rodríguez et al., 2011; Amata, 2013). This might be the cause of insignificant effect of replacing protein concentrate with $S$. cerevisiae on body weight and body weight gain. The results of this study are in agreement to findings of Owens and McCraken (2007), Morales-López et al., (2009) and Brümmer (2010) who found no adverse effect of using yeast and yeast product on body weight and body weight gain in broilers. Contray to this study, Chand et al. (2014) reported significantly $(P<0.05)$ higher body weight gain in broilers of different dietary treatments replacing soybean meal with $S$. cerevisiae as compared to control feed, although S. cerevisiae and soybean have more or less similar essential amino acid composition (Adedayo et al., 2011).

\section{Feed intake and FCR}

Insignificant differences in feed intake were observed among different dietary groups. The results of this study are in line to Chand et al. (2014), who have reported insignificant effect of replacing soybean meal with $S$. cerevisiae in broiler diet. Gao et al. (2008) have reported no effect on feed intake in broilers supplemented with $2.5,5$ and $7.5 \mathrm{~g} / \mathrm{Kg}$ yeast. Similar effect was reported by Hassanein and Soliman (2010). Contray to this study, Chen et al. (2009) and Sharif et al. (2012) have reported higher feed intake in broiler chicks as a result of supplementing yeast in the ration; whereas, Abou El-Naga (2012) have reported a significant decrease in feed intake as a result of using yeast in the ration. The positive effect of using $S$. cerevisiae may be due to the unidentifined growth factors along with other nutrients which are available in cells (Gao et al., 2008).

Thefore, it may be postulated that replacment of commercial protein concentrate with autolyzed $S$. cerevisiae did not affect the taste of the feed and thereby feed intake. Numerically lower FCR was observed in $25 \%$ and $50 \%$ replacement groups 


\section{Moniruzzaman and Mollah (2019) Bang. J. Anim. Sci. 48 (1):1-8}

as compared to control group. Chen et al. (2009) reported that presence of unidentified growth factors in yeast cells which act on intestinal villus and improve the gross energy absorption from feed. Moreover, yeast single cell protein has higher biological value (Sharif et al., 2012). These may be responsible for improved FCR in replacement groups. The findings of this study are consistent with the finding of Abou El- Naga (2012) and Yalçin et al. (2013). They found that addition of $S$. cerevisiae results improved FCR in broiler. In contrary to this study, Owens and McCracken (2007) reported no improvement of FCR as a result of using yeast and yeast products in broiler ration.

\section{Carcass characteristics}

No significant differences in dressing precentage, abdominal fat, gizzard, liver, heart, spleen and intestine among different dietary groups were observed in this study. The result of this study are in agreement with findings of Ozsoy and Yalçin (2011), Yalçin et al. (2013) and Chand et al. (2014) who have reported no effect of using yeast autolysate in feed on liver, gizzard, heart and dressing percentage in broilers. Contrary to this study, Onifade et al. (1998) reported that weight of liver, gizzard, heart and dressing percentage were significantly increased due to supplementation of yeast extracts. The result may vary due to different factors like form of feed, environment, quality of yeast protein, physiological functioning of different organs.

\section{Conclusion}

The findings of this study suggest that autolyzed S. cerevisiae might be used to replace protein concentrate at a level of $25 \%$ and $50 \%$ in broiler diet without compromising growth and carcass quality. However, further study with female chicks might help to recommend more precise inclusion level of autolyzed $S$. cerevisiae as a source of SCP in the broiler diet.

\section{Acknowledgement}

The authors acknowledge the financial support of Novus International Inc. (Novus Graduate Scholarship Program) and technical supports of Department of Poultry Science, Bangladesh Agricultural University, Mymensingh, Bangladesh.

\section{Conflict of interest}

We, the affiliated authors whose names are reported in the manuscript, hereby, declare that, we have NO affiliations with or involvement in any organization or entity with any financial interest or non-financial interests in the subject matter or materials discussed in this manuscript.

\section{References}

Abou El-Naga MK (2012). Effect of dietary yeast supplementation on broiler performance. Egyptian Poultry Science Journal 32(1):95-106.

Adedayo MR, EA Ajiboye, JK Akintunde and A Odaibo (2011). Single cell proteins: as nutritional enhancer. Advances in Applied Science Research 2(5):396-409.

Amata IA (2013). Yeast single cell protein: characteristics and metabolism. International Journal of Applied Biology and Pharmaceutical Technology 4(1):158-170.

Bacha U, M Nasir, A Khalique, AA Anjum and MA Jabbar (2011). Comparative assessment of various agro-industrial wastes for Saccharomyces cerevisiae biomass production and its quality evaluation as single cell protein. The Journal of Animal and Plant Sciences 21(4): 844-849.

Bekatorou A, C Psarianos and AA Koutinas (2006). Production of food grade yeasts. Food Technology and Biotechnology 44(3):407-415.

Brümmer M, C Jansen van Rensburg and CA Moran (2010). Saccharomyces cerevisiae cell wall products: The effects on gut morphology and performance of broiler chickens. South African Journal of Animal Science 40(1):14-21.

Chand N, Ihsanuddin and RU Khan (2014). Replacement of soybean meal with yeast single cell protein in broiler ration: the effect on performance traits. Pakistan Journal of Zoology 46(6): 1753-1758

Chen KL, WL Kho, SH You, RH Yeh, SW Tang and CW Hsieh (2009). Effects of Bacillus subtilis varnatto and Saccharomyces cerevisiae mixed fermented feed on the enhanced growth performance of broilers. Poultry Science 88:309-315.

Chowdhury SD (2013). Opportunities and challenges facing commercial poultry production in Bangladesh. In: Proceedings of the Eighth International Poultry Show and Seminar, WPSA$B B, 28$ February-01 March, 2013, Dhaka, Bangladesh, pp. 1-12.

Fernandez F, M Hinton and B van Gils (2002). Dietary mannanoligosaccharides and their effect on chicken caecal microflora in relation to Salmonella enteritidis colonization. Avian Pathology 31(1):49-58.

Gao J, HJ Zhang, SH Yu, SG Wu, I Yoon, J Quigley, YP Gao and GH Qi (2008). Effects of yeast culture in broiler diets on performance and immunomodulatory functions. Poultry Science 87(7): 1377-1384.

Hassanein SM and NK Soliman (2010). Effect of probiotic (Saccharomyces cerevisiae) adding to diets on intestinal microflora and performance of 
hy-line layer hens. Journal of American Science 6(11):159-169.

Morales-López R, E Auclair, F Garcia, E EsteveGarcia and J Brufau (2009). Use of yeast cell walls; $\beta-1,3 / 1,6$-glucans; and mannoproteins in broiler chicken diets. Poultry Science 88(3):601-607.

Nasseri AT, S Rasoul-Amini, MH Morowvat and $Y$ Ghasemi (2011). Single Cell Protein: Production and Process. American Journal of Food Technology 6(2):103-116.

Onifade AA, GM Babatunde, SA Afonja, SG Ademola and EA Adesina (1998). The effect of a yeast culture addition to a low-protein diet on the performance and carcass characteristics of broiler chickens. Poultry Science 77:44-47.

Owens B and KJ McCracken (2007). A comparison of the effects of different yeast products and antibiotic on broiler performance. British Poultry Science 48(1):49-54.

Ozsoy B and S Yalçin (2011). The effects of dietary supplementation of yeast culture on performance, blood parameters and immune system in broiler turkeys. Veterinary Journal of Ankara University 58:117-122.

R Core Team (2016). R: A language and environment for statistical computing. $R$ Foundation for Statistical Computing, Vienna, Austria.

Ravindra AP (2000). Value-added food: single cell protein. Biotechnology Advances 18(16):459479.

Rodríguez B, AA Canela, LM Mora, WF Motta, $P$ Lezcano and AC Euler (2011). Mineral composition of torula yeast (Candida utilis), grown on distiller's vinasse. Cuban Journal of Agricultural Science 45(2):151-154.

Shahryar HA, A Ahmadzadeh and A Lotfi (2012). Possibilities of inclusion of Saccharomyces cerevisiae as replacement for fish meal or poultry meat by-product in broiler chicken diet. Journal of Biological and Environmental Sciences 6(18):249-251.

Sharif M, MA Shahzad, S Rehman, S Khan, R Ali, ML Khan and K Khan (2012). Nutritional evaluation of distillery sludge and its effect as a substitute of canola meal on performance of broiler chickens. Asian-Australasian Journal of Animal Sciences 25(3):401-409.

Tangüler $H$ and $H$ Erten (2009). The effect of different temperatures on autolysis of baker's yeast for the production of yeast extract. Turkish Journal of Agriculture and Forestry 33(2):149-154.

Yalçın S, H Eser, S Yalçın, S Cengiz and Ö Eltan (2013). Effects of dietary yeast autolysate (Saccharomyces cerevisiae) on performance, carcass and gut characteristics, blood profile, and antibody production to sheep red blood cells in broilers. Journal of Applied Poultry Research 22(1):55-61.

Yamada EA and VC Sgarbieri (2005). Yeast (Saccharomyces cerevisiae) proteins concentrate: preparation, chemical composition, and nutritional and functional properties. Journal of Agricultural and Food Chemistry 53(10):3931-3936.

Yassine M, I Amar and R Raya (2013). Enrichment of the protein content of biomass derived from coastal remains of marine organisms to be used as poultry fodder. Journal of Entomology and Zoology Studies 1(5):43-47. 